\title{
EFFECT OF OXIDIZING MEDIUM ON SYNTHESIS GAS CONTENT AT SOLID FUEL GASIFICATION
}

\author{
Alexander Korotkikh ${ }^{1,2,}{ }^{*}$, Konstantin Slyusarskiy ${ }^{1}$, and Ivan Sorokin ${ }^{1}$ \\ ${ }^{1}$ National Research Tomsk Polytechnic University, 634050 Tomsk, Russia \\ ${ }^{2}$ National Research Tomsk State University, 634050 Tomsk, Russia
}

\begin{abstract}
Solid fuel gasification is promising technology in sphere of clean energy. The synthesis gas content for air-blown fixed bed gasification may be defined using Gibbs free energy minimization procedure. The minimization procedure was realized via steepest descent method. The feed consisted of steam, air and coal at standard conditions. The temperature and gas content were calculated at different ratios of coal/steam/air. It was found that optimal syngas content resulted at component ratio of $1.0 / 0.5 / 2.2$ with the ambient temperature of $1300 \mathrm{~K}$ and syngas heating power of $7.7 \mathrm{~kJ} / \mathrm{m}^{3}$.
\end{abstract}

\section{Introduction}

The energy consumption drastically grows last decades in the world: the electricity and primary energy consumption increased by 2.5 times [1]. However, the greenhouse gas specific emission per person of generated electricity is on the level of 1970 [1], despite recent progress in energy-generating technology. Together with population growth it makes the greenhouse problem more and more relevant as well as development of energy-effective technologies.

Gasification (organic matter conversion into combustible gas by means of partial oxidation) is one of the most promising technology to improve efficiency of fossil fuel usage and decrease its negative impact on environment. In general, syngas consists of carbon mono- and dioxide, hydrogen and steam. The exact concentration depends on many factors such as the temperature, pressure and fuel/oxidizer weight ratio. The large number of simultaneous chemical reactions in system makes their description extremely complex. The equilibrium composition of syngas may be defined using Gibbs free energy minimization procedure [2].

The equilibrium composition of synthesis gas for steam-air blown coal gasification at different coal/steam/air ratios as well as the adiabatic temperature were calculated. The feed properties were taken for T-grade bituminous coal of Kuznetskiy deposit (Kapitalnaya-2 mine, Osinniki).

\footnotetext{
* Corresponding author: korotkikh@tpu.ru
} 


\section{Mathematical model}

Gibbs free energy minimization methods are widely presented in scientific works. The method of steepest descent for such application was presented at the first time by White [3] and further modified by Koukkari [4] and is the most widespread in thermochemistry because of its simplicity and rapid convergence. Other methods (such as Newton method or method of internal points) are not so widespread and applied in some special spheres like geology or plasma physics.

Free Gibbs energy of enclosed single-phased multicomponent system may be calculated via equation:

$$
G=R T \sum_{i=1}^{m} n_{i}\left(\left(\mu_{i} / R T\right)_{i}+\ln \left(n_{i} / \sum_{i=1} n_{i}\right)\right)
$$

where $R$ is the gas constant, $\mathrm{J} /($ mole $\mathrm{K}) ; T$ is the temperature, $\mathrm{K} ; n_{i}$ is the substance amount $i$, mole; $\mu_{i}$ is the Gibbs molar potential of substance, $\mathrm{J} /$ mole. It may be defined with using equation:

$$
\mu_{i}=h_{i}-s_{i} T+R T \ln \left(p / p_{0}\right)
$$

where $h_{i}$ is substance molar enthalpy of formation at constant temperature, $\mathrm{J} / \mathrm{mole} ; s_{0}$ is the substance molar entropy at constant temperature, $\mathrm{J} /($ mole $\mathrm{K}) ; p_{0} / p$ are standard/current pressures in system, respectively, $\mathrm{Pa}$.

To meet material balance restrains for system which consisted of $N$ molecules and $M$ atoms on possible solution domain the following equation system was taken into account:

$$
\sum_{i \in N} a_{i j} n_{i}=b_{j}, j \in M, n_{i}>0
$$

where $a_{i j}$ is stoichiometric coefficient (number of $j$ type atoms in molecule $i$ ); $b_{j}$ is a total amount of $j$ type atoms in system, mole.

Gibbs free energy minimum was found using the steepest descent method by Koukkari algorithm [4]. The large number of substances with close to zero concentration badly influences on algorithm result preciseness. That's why the decision to choose six substances with expected significant content was made. The steam, hydrogen, methane, oxygen, carbon mono- and dioxide were chosen because of high concentration in feed and low free enthalpy values at standard conditions. The nitrogen presence in air and ash presence in coal was taken into account only in heat balance equations.

The thermal effect of system transition from initial into equilibrium state was defined via law of constant heat summation (Hess's law) [4]:

$$
\Delta H_{r}=\sum n_{i}^{p r} H_{f}^{p r}-\sum n_{i}^{f} H_{f}^{f}
$$

where $H_{f}$ is $i$ substance molar enthalpy of formation, $\mathrm{J} /$ mole. Indexes $f$ and $p r$ refer to feed and products of reaction, respectively.

The process was considered as autothermal than the heat effect of reaction was equal to difference between enthalpies of products and feed at preset temperature. The syngas heating power was defined using equation [5]:

$$
Q=\sum v_{i} Q_{i}
$$

where $v_{i}$ is molar concentration of $i$ substance in mixture; $Q_{i}$ is the heating power of $i$ substance in mixture, $\mathrm{J} / \mathrm{m}^{3}$.

The following assumptions were made:

1. The interactions between nitrogen and ash with syngas was not included.

2. The carbon conversion was considered equal to unity. 
3. The thermal losses during gasification were not taken into account.

4. The ash was considered to be solid at all temperatures.

5. The presence of condensed phase in system was neglected.

The thermochemical properties of substances were defined using open-source software CoolProp. The heat capacity value of ash was taken according to [6]. Algorithm was realized in MATLAB programming package.

The fuel properties were taken for T-grade coal of Kuznetskiy deposit. Coal chemical content was defined according to presented method [7]. The results of chemical content of studied solid fuel are presented in table 1.

Table 1. Solid fuel chemical content.

\begin{tabular}{|c|c|c|c|c|c|}
\hline \multicolumn{4}{|c|}{ Elemental content, wt. \% } & Humidity, wt. \% & $\begin{array}{c}\text { Ash content, } \\
\text { wt. \% }\end{array}$ \\
\hline $\mathrm{y}^{\mathrm{d}}$ & $\mathrm{H}^{\mathrm{d}}$ & $\mathrm{N}^{\mathrm{d}}$ & $\mathrm{S}^{\mathrm{d}}$ & & 18.4 \\
\hline 73.1 & 3.5 & 2.9 & - & 10.5 & 18 \\
\hline
\end{tabular}

\section{Results and discussion}

Results of the adiabatic temperature and heating power of syngas at the different ratio of $\mathrm{coal} / \mathrm{steam} /$ air at gasification of solid fuel are presented in figure 1 .

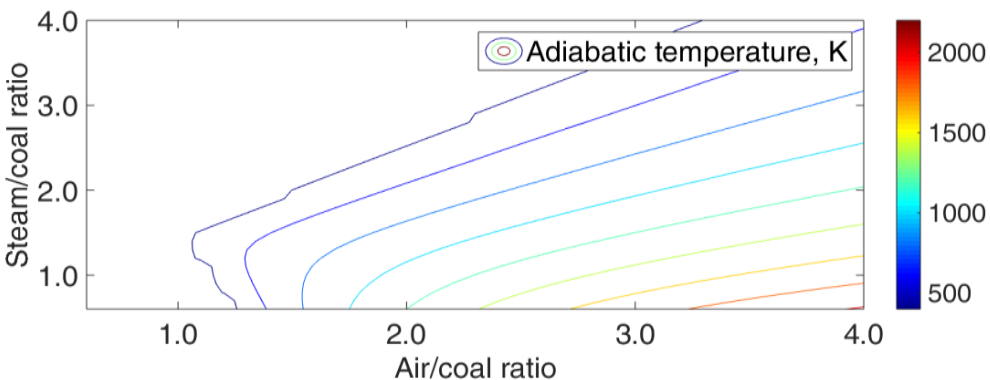

a)

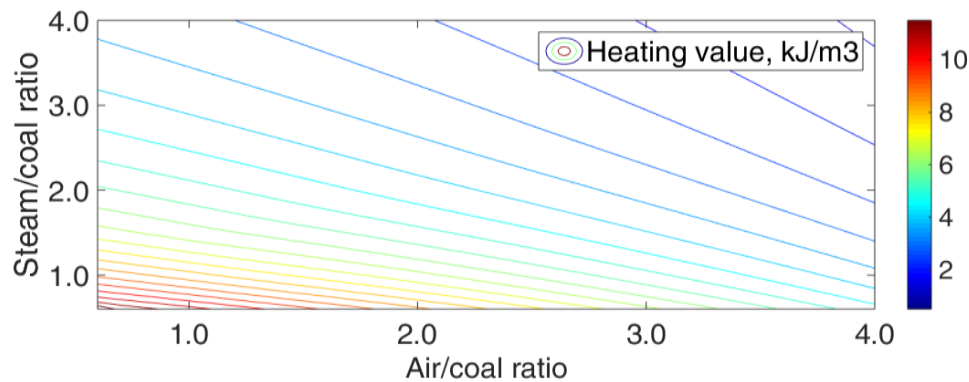

b)

Fig. 1. The adiabatic temperature (a) and syngas heating power (b) at various coal/steam/air ratio.

The maximal possible value of syngas heating power $11.1 \mathrm{~kJ} / \mathrm{m}^{3}$ is obtained at coal/steam/air ratio of 1.0/0.5/0.5 and resulted at the adiabatic temperature of $300 \mathrm{~K}$. This appear because of system stoichiometric properties - lack of oxygen promotes formation of combustible substances, even if they are thermochemically ineffective. In exploitation conditions it means that high heating power values as well as gasifier high efficiency values are correspond to allothermal processes. In real conditions, low temperature processes are rarely used because of process low intensity. The lowest temperature used are usually close 
to $1300 \mathrm{~K}$. The syngas maximal heating power at $1300 \mathrm{~K}$ is $7.7 \mathrm{~kJ} / \mathrm{m}^{3}$ and obtained at $\mathrm{coal} / \mathrm{steam} /$ air ratio with values of $1.0 / 0.5 / 2.2$. The adiabatic temperature, in contrary, is increased with growth of coal/steam/air ratio, because of air content and reaches its maximum with coal/steam/air ratio of 1.0/0.5/4.0, the temperature value of $2100 \mathrm{~K}$ and the heating power of $4.5 \mathrm{~kJ} / \mathrm{m}^{3}$.

\section{Conclusion}

The mathematical model of single-phased multicomponent system equilibrium content was realized via Gibbs free energy minimization algorithm. The steepest descent method was used. The syngas heating power and adiabatic temperature were defined at different weight ratio of steam and air in the range of 0.5-4.0. The Kuznetskiy deposit bituminous coal was used as model fuel for calculation. The maximum value of syngas heating power corresponds to minimal oxidizer flow, while the adiabatic temperature increases with air expenditure and decreases with steam expenditure. The maximum heating power value is $11.1 \mathrm{~kJ} / \mathrm{m}^{3}$ at the temperature of $300 \mathrm{~K}$ and coal/steam/air ratio $1.0 / 0.5 / 0.5$ and the maximum temperature is $2100 \mathrm{~K}$ at $1.0 / 0.5 / 4.0 \mathrm{coal} / \mathrm{steam} /$ air ratio with heating power of $4.5 \mathrm{~kJ} / \mathrm{m}^{3}$. The maximum heating power of $7.7 \mathrm{~kJ} / \mathrm{m}^{3}$ is obtained for coal/steam/air ratio $1.0 / 0.5 / 2.2$ and at temperature of $1300 \mathrm{~K}$.

\section{Reference}

1. BP Statistical Review of World Energy, June (2015)

2. V. Liso, G. Cinti, M.P. Nielsen, U. Desideri Appl. Therm. Eng. (to be published)

3. W.B. White, S.M. Johnson, G.B. Dantzig, J. Chem. Phys. 28 (1958)

4. P. Koukkari, Introduction to constrained Gibbs energy methods in process and materials research (VTT Technology, Espoo, 2014)

5. Z. Chen, Y. Shi, D. Lai, S. Gao, Z. Shi, Y. Tian, G. Xu, Fuel 176 (2016)

6. R.V. Krishnan, G. Jogeswararao, K. Ananthasivan, J. Therm. Anal. Calorim. 121 (2016)

7. V. Patil-Shinde, S. Saha, B.K. Sharma, S.S. Tambe, B.D. Kulkarni, Chem. Eng. Commun. 203 (2016) 